\section{Actualización en el manejo de heridas}

\author{
Update in wound management
}

\section{Dr. Gastón Domínguez-Saavedra,* Dr. Juan Miguel Hernández-Galván}

Palabras clave: Heridas, cicatrización, apósitos.

Keywords: Wounds, healing, dressings.

\section{RESUMEN}

Las heridas agudas complicadas y las heridas crónicas siempre han estado presentes en la práctica médica. Lamentablemente, el cuidado que a ellas se les dedica no es el adecuado y muchas veces es empírico. Los altos costos en los servicios de salud y la mala calidad de vida de los pacientes que las sufren generaron en los últimos 20 años el desarrollo de tecnologías para el cierre rápido, óptimo y costo-efectivo de estas lesiones. Apareció el concepto de ambiente húmedo con el que se desarrollaron apósitos o vendajes especializados. El desarrollo de esta tecnología en heridas ha crecido a pasos agigantados, pero en nuestro país aún existe resistencia a su uso, a pesar de la evidencia científica existente. Es importante que los cirujanos conozcan este arsenal terapéutico y enfoquen las heridas de manera holística y no como lesiones aisladas de pacientes crónicos. Además, las nuevas generaciones de cirujanos deben entrenarse en sus años de residencia en el uso de estos apósitos, como ya se hace en Estados Unidos y Europa; incluso, se debe considerar esta área como una subespecialidad del cuidado quirúrgico. Existen dos tipos de curaciones: la tradicional, que usa apósitos de baja tecnología (gasas) y la avanzada, que usa apósitos con sustancias activas que interactúan con el microambiente de la herida, por ejemplo, hidrocoloides, alginatos o colágena, entre otros. El objetivo de esta revisión es identificar todos los materiales con los que contamos, desde productos orgánicos hasta aparatos de la más alta tecnología para la curación de heridas y en qué momento utilizarlos.

\section{ABSTRACT}

Complicated acute wounds and chronic wounds have always been present in medical practice. Unfortunately, the care given to them is not adequate and is often empirical. The high costs in health services and the poor quality of life of the patients who suffer because of them, brought about the development of technologies for the rapid, optimal and cost-effective closure of these injuries in the last 20 years. The concept of a humid environment appeared, with which specialized dressings or bandages were developed. The development of this technology has grown by leaps and bounds; but, in our country, there is still resistance to its use, despite the existing scientific evidence. It is important that surgeons are aware of this therapeutic arsenal and approach wounds holistically, and not as isolated injuries in chronic patients. In addition, new generations of surgeons must be trained in their years of residency in the use of these dressings, as is already done in North America and Europe. One should go as far as consider this a subspecialty of surgical care. There are two types of healing: the traditional, which uses low-tech dressings (gauze) and the advanced, which uses dressings with active substances that interact with the wound's microenvironment, such as: hydrocolloids, alginates, or collagen, among others. The objective of this review is to identify all the materials we have, from organic products to state-of-the-art devices for wound healing and when to use them.

\section{INTRODUCCIÓN}

* Médico residente de Cirugía General.

* Médico adscrito al Servicio de Cirugía

General.

Hospital Universitario de Saltillo, Saltillo, Coahuila de Zaragoza, México.
$\mathrm{E}_{\text {curación de las heridas con la formación }}^{\mathrm{n} \text { la antiguedad los médico asocian la }}$ de pus, por lo que las cubrían con apósitos y emplastos para que éste se produjera, pero no fue hasta que Ambrosio Paré, padre de la ciru- gía moderna, descubriera que sólo el mantenimiento de la herida limpia y cubierta llevaba a una evolución más satisfactoria de la misma. Razón por la que, a partir de ese momento, se han buscado insumos y materiales para llevar a una buena evolución de las heridas con las que hoy en día estamos en contacto todo el

Citar como: Domínguez-Saavedra G, Hernández-Galván JM. Actualización en el manejo de heridas. Cir Plast. 2021; 31 (3): 124-136. https://dx.doi.org/10.35366/103715 
personal médico. ${ }^{1}$ Contamos con gran cantidad de materiales para ayudar a la cicatrización de heridas de una forma óptima; sin embargo, aún con todos los avances e información no estamos capacitados para saber cómo usarlos y cuándo indicarlos.

La enfermedad siempre ha acompañado la historia de la humanidad y gran parte de esa historia está representada en el manejo de las heridas, ya sean agudas, como las heridas postraumáticas o postquirúrgicas, o crónicas como las úlceras de los miembros inferiores.

El manejo de las heridas ha sido abandonado por los médicos y especialmente por los cirujanos y su cuidado ha quedado en manos de las enfermeras. Han representado siempre un reto para el médico y desesperanza para el paciente, ya que son patologías que difícilmente se curan si no se les da el tratamiento adecuado; representan altos costos para los servicios de salud y generan un detrimento muy importante en la calidad de vida de los pacientes.

Todos los cirujanos nos vemos enfrentados en algún momento a heridas de difícil manejo. La aplicación de terapias basadas en la experiencia propia o de terceros, sin estudios aleatorios o basados en la evidencia, ha perpetuado antiguas creencias y ha hecho de las curaciones algo poco científico, por lo que aburre y se delega a personal no capacitado.

El entendimiento adecuado de la fisiología del microambiente de una herida desde el punto de vista molecular, infeccioso y genético, el manejo multidisciplinario y el conocimiento de la tecnología de heridas nos permitirán tratar estas enfermedades con rigor científico y sentido crítico.

En la actualidad, el desarrollo de la tecnología de apósitos asociado a la valoración holística de los pacientes con heridas ha disminuido las complicaciones y los costos y ha mejorado la tasa de curación de estas entidades.

Es muy importante para las nuevas generaciones de médicos y cirujanos conocer el arsenal diagnóstico y terapéutico para el manejo de heridas complejas para optimizar la calidad de vida del paciente y ahorrar recursos, dejando atrás los conceptos folclóricos carentes de evidencia científica.

En Estados Unidos y Europa, el cuidado de las heridas es parte fundamental del en- trenamiento de los residentes de cirugía y desde hace ya varios años se considera una subespecialidad médico-quirúrgica, tanto para enfermeras como para cirujanos.

Antecedentes. El inicio de la medicina se da a la par de la aparición del hombre por la necesidad de protegerse y curarse, por lo que encontró plantas y sustancias, algunas de ellas las seguimos utilizando el día de hoy. Se tiene registro desde el año 3,000 a.C. de un manuscrito para la fabricación de medicamentos. En Egipto utilizaban el aceite de ricino para curar heridas y zonas irritadas del cuerpo y también usaban el pan fermentado porque observaron un efecto beneficioso sobre las heridas. El Papiro de Edwin Smith trata principalmente de heridas, fracturas y luxaciones con aplicaciones de compuestos de grasas animales, miel y tejidos con algodón y describe diferentes tipos de sutura de heridas. ${ }^{1,2}$

Los hebreos tienen registrada la preparación de ungüentos para la curación de heridas. En la India, Susruta describió el uso de vendajes y apósitos con las indicaciones de uso para cada uno y fue el primer antecedente de la reconstrucción de orejas y nariz. Los pueblos precolombinos curaban las heridas con una mezcla de hierbas astringentes o sustancias obtenidas de huevos de diferentes aves y las cubrían con plumas o vendas hechas de piel. Los aztecas abrían los abscesos y flemones con bisturís de obsidiana y colocaban tortillas de maíz afectadas con fungosis y suturaban las heridas con cabellos. El pueblo inca utilizaba diversas sustancias como la coca, el bálsamo de benjuí, los aceites de pepita y el sulfato cúprico para curar sus heridas.

En la Grecia antigua, en la época hipocrática, la curación de heridas y úlceras se realizaba mediante la limpieza de éstas y la aplicación de sustancias minerales $y / o$ vegetales acompañada siempre de vino y drenaban las heridas purulentas. Durante las cruzadas, el cirujano tuvo la oportunidad de observar el proceso de cicatrización. En aquel tiempo hubo médicos como Ugo de Lucca, su hijo Teodorico y Henri de Mondeville, por mencionar algunos, que concluyeron que el mejor manejo para las heridas era mantenerlas limpias, sin que fuera necesaria la formación de pus, ya que éste era más una complicación que parte de la cura- 
ción. ${ }^{2}$ Guillermo de Saliceto, en el siglo XIII, en su Chirurgia Magna, menciona que el manejo adecuado de las heridas es mantenerlas limpias, suturándolas lo más pronto posible. Podemos darnos cuenta de que a partir de esa época empieza el manejo de las heridas manteniéndolas limpias, pero no es sino hasta el siglo XV, cuando Paré descubrió que las heridas tratadas con limpieza con esencia de rosas y cobertura pronta tenían un resultado más satisfactorio y con menos inflamación que las tratadas con aceite hirviendo. ${ }^{1}$

Ya en el siglo XIX y XX se da un salto en cuanto al conocimiento de microorganismos que son capaces de producir enfermedad y por ende, contaminación de las heridas. Es así como Semmelweis incorporó un sistema de asepsia que, si bien no fue totalmente aceptado por la comunidad médica, abrió la puerta para que se iniciara el uso de la asepsia en los hospitales. Lister también observó que para obtener buenos resultados en el manejo de heridas, tenía que mantenerlas libres de toda contaminación, así que aplicaba ácido carbólico sobre el paciente al momento de realizar cirugías y esto lo comprobó al conocer los estudios de Pasteur. Estos tres personajes permitieron que se establecieran las bases de la asepsia y la antisepsia. ${ }^{1}$ A partir de una conferencia dictada por Lister, Robert Wood Johnson inicia una investigación para crear un apósito antiséptico en forma de gasa impregnada con yodoformo con el fin de lograr la antisepsia de la herida y favorecer su curación. 3,4 En 1963, Winter y colaboradores publicaron que al mantener las heridas en un ambiente húmedo se curaban mejor que las expuestas al aire, ya que la humedad impide la deshidratación y la desecación de la misma con una interfase entre la herida y el ambiente. ${ }^{3,5}$ Actualmente se llevan a cabo proyectos de investigación para entender el proceso molecular de la cicatrización y con ello dar el manejo más adecuado para la curación de heridas y evitar sus complicaciones como la infección y la cronicidad, para esto contamos con una gran variedad de suturas, adhesivos, materiales de curación, etcétera.

\section{Cicatrización}

Después de un traumatismo en la piel se forma una herida y el proceso de curación se inicia de inmediato. En función del tipo de herida, la epidermis (la parte superior de la piel) y la dermis (la parte intermedia de la piel con capilares sanguíneos) pueden quedar destruidas y tienen que ser restauradas mediante la reparación de la herida. Se trata de un proceso muy complejo que hoy día es todavía objeto de una investigación intensiva. El proceso de curación de las heridas es complejo e intervienen varios procesos celulares y moleculares que aún no se han entendido en su totalidad, pero para su estudio se han dividido en tres fases principalmente. ${ }^{6}$ La respuesta inmediata a la lesión es la vasoconstricción, que es causada por las prostaglandinas y los tromboxanos; las plaquetas se adhieren a la colágena expuesta y se libera el contenido de éstas en gránulos, mientras que el factor tisular activa la cascada de coagulación y las plaquetas. Esta matriz y el control de la coagulación ayudan a la cicatrización. ${ }^{7}$

Fases de la cicatrización (Figura 1):

1. Fase de respuesta vascular y coagulación de la sangre

2. Fase de inflamación

3. Fase de proliferación

4. Fase de remodelación/maduración

\section{Respuesta vascular y coagulación de la sangre (primeras 24 horas)}

Inmediatamente después de la lesión, la sangre penetra en la herida desde los vasos sanguíneos dañados. La sangre retira, por arrastre, los cuerpos «extraños», lo que contribuye a prevenir la infección (primer mecanismo de limpieza). Después de algunos segundos los vasos se contraen para reducir el sangrado. Células sanguíneas especiales denominadas plaquetas se adhieren unas a otras para formar un tapón. Este agregado detiene la hemorragia al taponar el vaso sanguíneo lesionado. Para seguir estabilizando el tapón plaquetario, el proceso de coagulación produce fibrina, necesaria para la coagulación sanguínea.

\section{Inflamación (de 24 a 48 horas)}

Esta fase de la curación se caracteriza por la formación de exudado y enrojecimiento de la 


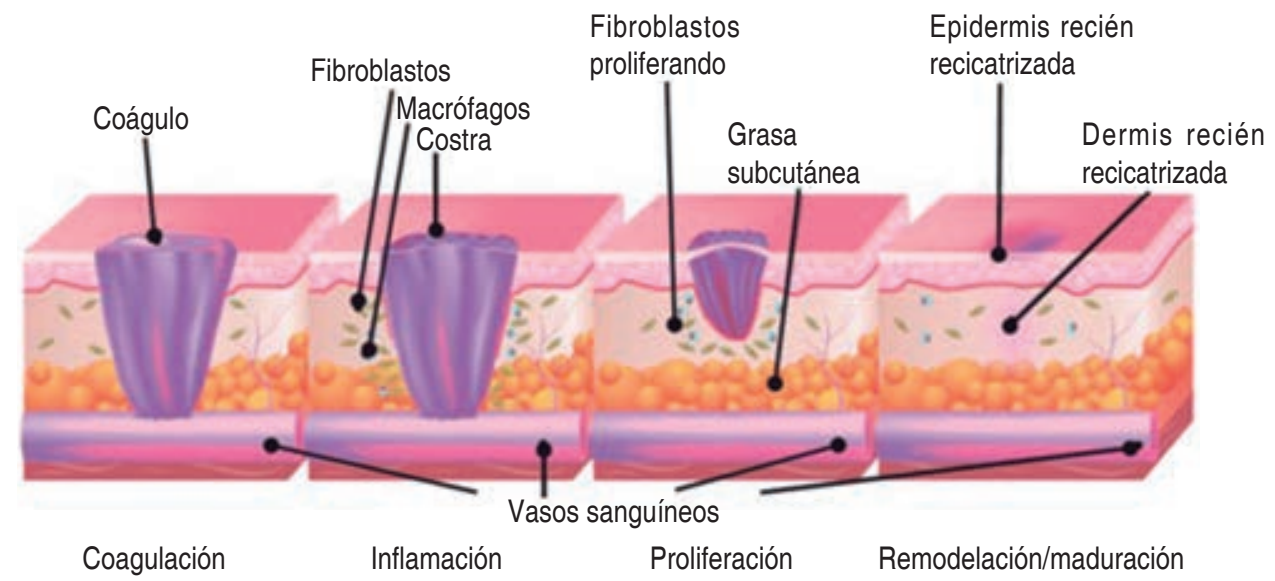

Figura 1: Fases de cicatrización.

piel circundante. Nada tiene que ver con la infección, sino que es causada por dos acontecimientos que aparecen principalmente durante la fase inflamatoria de la curación.

En primer lugar, los leucocitos (las Ilamadas células inflamatorias: primero neutrófilos y luego macrófagos) invaden el tejido lesionado y comienzan a limpiar la zona de desechos, tanto tejidos muertos y contaminantes como bacterias. En segundo lugar, las plaquetas y las células inflamatorias liberan mediadores, como los factores de crecimiento, para desencadenar el ulterior proceso de curación. 7,8

\section{Fase de proliferación (de cuatro a 14 días)}

La epitelización ocurre temprano en la reparación de la herida, depende de la proliferación y migración de células epiteliales desde los bordes de la herida y de cualquier remanente de los anexos de la piel (folículos pilosos, glándulas sebáceas y sudoríparas). La estimulación se lleva a cabo mediante el factor de crecimiento epidérmico (EGF) y el factor de crecimiento transformante alfa (TGF- $\alpha)^{7}$

La angiogénesis, estimulada por el factor de necrosis tumoral alfa (TNF- $\alpha$ ), está marcada por la migración de las células endoteliales y la formación de capilares, que es crucial para la apropiada curación de la herida. ${ }^{7}$ La granulación es la parte final de esta fase, requiere nutrientes que son llevados por los capilares; en ella los fibroblastos comienzan a migrar al sitio lesionado y empiezan a sintetizar colá- gena desorganizada y a proliferar. Las señales principales para los fibroblastos son el factor de crecimiento derivado de plaquetas (PDGF) y el factor de crecimiento epidérmico (EGF). ${ }^{7}$

\section{Fase de remodelación/maduración (día ocho hasta un año)}

Esta fase se caracteriza por el depósito de colágena en una bien organizada red. La colágena que se deposita al principio es más delgada y está orientada paralela a la piel (colágena tipo III). Con el paso del tiempo, ésta se reabsorbe y se deposita una colágena más fuerte y organizada a lo largo de las líneas de estrés. ${ }^{7}$ La síntesis de colágena dura aproximadamente de cuatro a cinco semanas, pero el volumen aumenta a un año de la lesión. . $^{8}$

Tras el cierre de la herida, el tejido recién formado no es idéntico al tejido original. En los casos en que sólo se afecta la epidermis no se forma cicatriz (regeneración). Si se lesiona la dermis se formará una cicatriz (reparación normal). Los trastornos de la curación de la herida pueden propiciar una formación cicatricial insuficiente o excesiva.

El proceso de remodelado puede necesitar años.

Los aumentos de la temperatura y la presión son factores conocidos que aceleran el proceso de remodelado y que pueden utilizarse para reducir la cicatriz. Las últimas innovaciones son los apósitos hidroactivos de poliuretano. 
Para resumir las fases de la curación de una herida cabe destacar que las células siguientes desempeñan un papel importante:

1. Las plaquetas junto con la fibrina detienen o cohíben la hemorragia.

2. Los leucocitos (neutrófilos primero y macrófagos después) limpian la herida.

3. Los fibroblastos forman colágena nueva para reemplazar el tejido perdido.

4. Los queratinocitos forman una nueva epidermis.

\section{Tipos de lechos de la herida}

Presentamos en este trabajo seis tipos de tejido en el lecho de las lesiones: ${ }^{10}$

1. Granulación.

2. Biofilm fibrina naturalizada

3. Biofilm bacteriano

4. Necrosis

4.1. Film de fibrina desnaturalizada

4.2. Húmeda o esfacelos

4.3. Necrosis seca en placa

4.4. Hematoma disecante

5. Tejido graso

6. Epitelio

\section{Preparación del lecho de la herida}

Hay cuatro componentes para la preparación del lecho de la herida que atienden las diferentes alteraciones fisiopatológicas subyacentes a las heridas. ${ }^{11}$ La European Wound Management Association (EWMA) describió una estrategia dinámica llamada TIME, que resume los cuatro puntos clave para estimular el proceso de curación natural. ${ }^{12,13}$

1. T (Tissue/Tejido): control del tejido no viable.

2. I (Infection/Infección): control de la inflamación.

3. $M$ (Moisture/Humedad): control del exudado.

4. E (Edge/borde): estimulación de los bordes epiteliales.

Más de 10 años después de la creación de este esquema, a pesar de los avances en las técnicas empleadas y la mayor evidencia disponible, esta estrategia sigue teniendo aplicabilidad.
Sin embargo, una crítica que se podría hacer es que se trata de un enfoque centrado en el manejo óptimo del lecho de la herida, sin tener en cuenta otros factores como el impacto biopsicosocial de la lesión en nuestros pacientes. Por ello, la estrategia TIME ha de enmarcarse como parte del manejo integral del enfermo que incluya, además del tratamiento local de la herida, la implementación de planes para obtener los objetivos definidos, el monitoreo de los productos utilizados y su tolerancia, la evaluación continua mediante herramientas de medida de curación y de calidad de vida. ${ }^{12-14}$

\section{T (Tissue/Tejido): control del tejido no viable}

Se debe retirar el tejido no vascularizado, ya que impide el proceso de curación, por lo que el desbridamiento proporciona un ambiente que estimula la acumulación de tejido sano y así una curación más pronta.

\section{I (Infection/Infección): control de la inflamación}

Las heridas son a menudo colonizadas con organismos bacterianos o fúngicos, en parte porque estas heridas permanecen abiertas durante periodos prolongados; también se relaciona con otros factores como la mala circulación de la sangre, la hipoxia y las enfermedades subyacentes. Una carga bacteriana por arriba de $10^{6}$ organismos o más por gramo de tejido afecta la cicatrización, por lo que es importante mantener libre la herida de contaminación bacteriana.

\section{M (Moisture/Humedad): control del exudado}

Se ha comprobado que el mantener húmedas las heridas acelera el proceso de epitelización y esto ha llevado al desarrollo de una amplia gama de apósitos que conservan la humedad y promueven la curación de las heridas. Se ha observado que el exudado de las heridas crónicas y agudas tiene diferentes propiedades; por ejemplo, en las heridas agudas, el exudado estimula la proliferación de fibroblastos, queratinocitos y células endoteliales; por el contrario, en las heridas crónicas el exudado bloquea la proliferación celular y la angiogénesis y con- 
tiene metaloproteinasas que rompen la matriz extracelular.

\section{E (Edge/borde): estimulación de los bordes epiteliales}

La curación efectiva de las heridas requiere del restablecimiento de un epitelio intacto y de las funciones de la piel. Este proceso de epitelización se puede ver afectado cuando hay fallas en la matriz celular o hay isquemia, por lo que se llega a inhibir la migración de queratinocitos o su adhesión.

Son el conjunto de materiales del que disponemos para favorecer el proceso de cicatrización. Existen diferentes tipos y clasificaciones, pero básicamente se diferencian según su localización y modo de acción.

Según su localización, los apósitos se clasifican en primarios y secundarios. Los primarios son aquéllos que están en contacto directo con la herida y los secundarios, los que protegen al apósito primario o tienen funciones de absorción. Según su modo de acción, los apósitos se clasifican en activos y pasivos.

\section{Curación convencional}

Es aquélla que se nos enseñó en las facultades de medicina, la cual usa materiales de baja absorción y alta capacidad de desecación, representados por gasa y algodón en forma de compresas, apósitos o torundas.

Estos materiales son pasivos en el sentido de que no intervienen en el proceso de cicatrización y peor aún, lo lentifican y complican. Varios estudios aleatorios han demostrado que estos materiales disminuyen la cicatrización, aumentan los costos, elevan la incidencia de infección y generan más dolor. ${ }^{15}$

Con este método, las curaciones se caracterizan por ser de frecuencia diaria y dolorosa, ya que en cada evento de curación se remueve tejido sano de manera cruenta, con sangrado y dolor. Son más costosas porque implican gastos para el proveedor de salud y para el paciente en cada consulta para la curación y alargan el periodo de cicatrización, haciéndolo más susceptible a complicaciones locales o sistémicas.

Lamentablemente, estas curaciones se caracterizan por un alto nivel de empirismo por parte de las personas que las realizan, sumado a conceptos de cultura popular y folclor que van en detrimento de la atención profesional como el uso de plantas, azúcares tipo panela, soluciones antisépticas como el peróxido de hidrógeno, soluciones yodadas o con cloro, que se ha demostrado que lentifican y complican el proceso de cicatrización, tanto en heridas agudas como crónicas. ${ }^{16}$

\section{Curación avanzada}

La curación avanzada se basa en el principio del ambiente húmedo, utiliza apósitos de alta tecnología que favorecen la cicatrización al estimular el microambiente de la herida. Son curaciones realizadas con una periodicidad de cuatro a seis días, según el tipo de herida, sin dolor y son costo-efectivas; además favorecen el cierre rápido y óptimo de todo tipo de heridas. ${ }^{16-18}$

\section{Tipos de heridas}

En una reunión de consenso realizada en $1994^{19}$ se definieron conceptos y guías para que los investigadores y clínicos interesados en el tema tuvieran un lenguaje común. Así, «herida» se definió como toda disrupción de estructuras anatómicas y funcionales normales; sin embargo, existen innumerables clasificaciones de las heridas, la mayoría de difícil aplicación clínica.

La separación más importante es determinar si la herida es aguda o crónica con base en los conceptos de orden y temporalidad.

Una herida aguda es aquélla que tiene un tiempo de evolución menor de 30 días y sigue un proceso de reparación ordenado dentro de un tiempo adecuado hasta restaurarse la integridad anatómica y funcional del tejido inicialmente lesionado. Por ejemplo, heridas limpias después de procedimientos quirúrgicos o abrasiones superficiales después de traumas.

Por otro lado, las heridas crónicas son aquéllas que no siguen un proceso de reparación normal; se estancan en alguna fase de la cicatrización sin que se restaure la integridad anatómica ni funcional del tejido lesionado. Por ejemplo, úlceras venosas de los miembros inferiores o úlceras por presión. 
En estas definiciones, el concepto de orden se refiere a la secuencia de eventos biológicos que ocurren en la reparación de una herida y el concepto de temporalidad se refiere al tiempo que demora el proceso.

\section{Apósitos}

Son el conjunto de materiales del que disponemos para favorecer el proceso de cicatrización. Existen diferentes tipos y clasificaciones, pero básicamente se diferencian según su localización y modo de acción (Tabla 1).

Según su localización, los apósitos se clasifican en primarios y secundarios. Los primarios son los que están en contacto directo con la herida y los secundarios los que protegen al apósito primario o tienen funciones de absorción.

Según su modo de acción, los apósitos se clasifican en pasivos y activos.

\section{Productos pasivos}

Son aquéllos que no interactúan con la herida, tienen alta capacidad de desecación y poca absorción y además propician la infección. Son los que se usan en la curación convencional. El más representativo es la gasa tejida o prensada, material de origen natural que destruye el tejido de granulación. ${ }^{16}$

\section{Productos activos}

Son los utilizados en la curación avanzada y son activos porque interactúan con la herida favoreciendo su proceso de cicatrización.

Las características de estos apósitos son:

1. Proporcionan un ambiente húmedo

2. Son estériles

3. Tienen capacidad de absorción

4. Brindan protección contra la infección

5. No son adherentes

6. No son tóxicos ni alergénicos

7. No dejan residuos en la herida

8. Se adaptan a los contornos anatómicos

9. Son resistentes

10. Son costo-efectivos

11. Son fáciles de usar

12. Disminuyen el dolor y el olor (Tabla 1)

\section{Técnicas avanzadas en el cuidado de heridas}

Constituyen todas aquellas tecnologías diferentes a los apósitos especializados para el cierre de heridas agudas o crónicas de difícil manejo. Entre estas tecnologías tenemos las siguientes:

\section{Sistema de presión negativa o Vacuum Assisted Closure (VAC ${ }^{\circledR}$ )}

A principios de los años 90, Argenta y Morykwas introdujeron la terapia de presión negativa con la primera publicación en 1997. Ésta ha sido la mayor innovación en el manejo de heridas. El dispositivo consiste en un adhesivo con un tubo conectado a un recipiente de recolección y una fuente de vacío. Se basa en el uso de presión negativa o subatmosférica para el manejo de heridas complejas que estimula la aparición del tejido de granulación y controla el exudado. La presión negativa sobre las heridas genera un aumento de mitosis y angiogénesis, lo que permite la contracción de la herida y aparición rápida de tejido de granulación.

El material de la interfaz es una esponja de poliuretano de poro abierto, hidrófobo, que tiene que sellar adecuadamente para mantener el vacío o el aire se fuga causando desecación. Otros materiales que se utilizan son esponjas con alcohol polivinílico o gasas. Éstos deben actuar como una interfaz para distribuir el vacío a lo largo de la herida y permitir que se eliminen los fluidos. La presión negativa que se aplica puede ser constante o intermitente; se recomienda una presión de $125 \mathrm{mmHg}$, pero puede aumentarse hasta $175 \mathrm{mmHg}$. Requiere de cambios cada 48 a 72 horas.

Las indicaciones son pie diabético, úlceras por presión, abdomen abierto, fístulas intestinales enterocutáneas y heridas postraumáticas, entre otras. Se contraindica en pacientes con heridas con necrosis y alto grado de contaminación y heridas de origen tumoral. El uso de VAC sobre estructuras vasculares es una contraindicación relativa (Figura 2). ${ }^{20,21}$

\section{Terapia de oxígeno hiperbárico}

Se basa en el suministro de oxígeno al 100\% dentro de una cámara presurizada con el fin de aumentar el aporte de oxígeno a los tejidos por 


\begin{tabular}{|c|c|c|c|c|c|c|}
\hline Apósitos & Características & Exudados & Indicaciones & Ventajas & Desventajas & Ejemplos \\
\hline Alginatos & $\begin{array}{l}\text { Se produce a partir } \\
\text { de algas pardas } \\
\text { Forma un gel cuando } \\
\text { el calcio contenido } \\
\text { en el apósito se } \\
\text { intercambia por } \\
\text { sodio en la herida } \\
\text { Absorbe } 20 \text { veces su } \\
\text { peso } 0^{9} \\
\text { Ideal para rellenar } \\
\text { espacios muertos }\end{array}$ & Abundante & $\begin{array}{c}\text { En heridas } \\
\text { superficiales y } \\
\text { profundas } \\
\text { Heridas } \\
\text { infectadas } \\
\text { Desbridamiento } \\
\text { autolítico }\end{array}$ & $\begin{array}{l}\text { Absorbe exudado } \\
\text { de las heridas } \\
\text { Permite el } \\
\text { intercambio de } \\
\text { gas, mientras } \\
\text { la protege de la } \\
\text { contaminación }\end{array}$ & $\begin{array}{l}\text { Requiere de } \\
\text { un apósito } \\
\text { transparente } \\
\text { Puede } \\
\text { deshidratar las } \\
\text { heridas con } \\
\text { exudado mínimo } \\
\text { Causa dolor al } \\
\text { removerlo } \\
\text { Contraindicado } \\
\text { en quemaduras } \\
\text { de tercer grado } \\
\text { Debe cambiarse } \\
\text { diario }\end{array}$ & $\begin{array}{c}\text { Algisite }^{\circledR} \\
\text { Aquacel }^{\circledR} \\
\text { Silvercell }^{\circledR}\end{array}$ \\
\hline Esponjas & $\begin{array}{c}\text { Polímero de } \\
\text { poliuretano } \\
\text { hidrofílico } \\
\text { Proporciona } \\
\text { aislamiento térmico } \\
\text { Permite intercambio } \\
\text { gaseoso }\end{array}$ & Moderado & $\begin{array}{c}\text { En heridas } \\
\text { superficiales y } \\
\text { profundas } \\
\text { Desbridamiento } \\
\text { autolítico } \\
\text { Heridas } \\
\text { infectadas } \\
\text { Protección y } \\
\text { relleno }\end{array}$ & $\begin{array}{l}\text { No adherente } \\
\text { Se puede } \\
\text { cambiar diario y } \\
\text { hasta siete días } \\
\text { Adecuada } \\
\text { dispersión del } \\
\text { exudado }\end{array}$ & $\begin{array}{l}\text { No recomendado } \\
\text { en heridas } \\
\text { cavitadas } \\
\text { Puede } \\
\text { deshidratar } \\
\text { heridas con } \\
\text { exudado mínimo } \\
\text { No recomendado } \\
\text { en heridas secas } \\
\text { o escaras }\end{array}$ & $\begin{array}{c}\text { Allevyn }^{\circledR} \\
\text { Tielle }^{\circledR}\end{array}$ \\
\hline Hidrocoloides & $\begin{array}{c}\text { Combinación de } \\
\text { materiales como } \\
\text { gelatinas, pectinas, } \\
\text { elastómeros y } \\
\text { policarbometilcelulosa } \\
\text { Altamente oclusivos } \\
\text { Superficie adherente } \\
\text { Impermeable a las } \\
\text { bacterias } \\
\text { Absorción de la } \\
\text { humedad de forma } \\
\text { paulatina } \\
\text { Diversos tamaños y } \\
\text { formas }\end{array}$ & Mínimo & $\begin{array}{c}\text { Heridas } \\
\text { superficiales y } \\
\text { profundas } \\
\text { Heridas que } \\
\text { requieren } \\
\text { humedad y tejido } \\
\text { de granulación } \\
\text { Desbridamiento } \\
\text { autolítico }\end{array}$ & $\begin{array}{l}\text { Reducción del } \\
\text { dolor } \\
\text { Altamente } \\
\text { oclusivos } \\
\text { Se acopla a la } \\
\text { herida } \\
\text { Recambio hasta } \\
\text { siete días } \\
\text { Barrera contra } \\
\text { bacterias y } \\
\text { contaminantes }\end{array}$ & $\begin{array}{l}\text { Pueden dejar } \\
\text { residuos en la } \\
\text { superficie de la } \\
\text { herida } \\
\text { No recomendado } \\
\text { en heridas } \\
\text { infectadas, } \\
\text { exudado } \\
\text { abundante o } \\
\text { herida con } \\
\text { trayectos } \\
\text { fistulosos } \\
\text { Puede promover } \\
\text { infección por } \\
\text { anaerobios } \\
\text { Puede promover } \\
\text { exceso de } \\
\text { granulación } \\
\text { El olor se } \\
\text { confunde con } \\
\text { infección }\end{array}$ & $\begin{array}{l}\text { DuoDerm }^{\circledR} \\
\text { Tegasorbb }^{\circledR}\end{array}$ \\
\hline
\end{tabular}




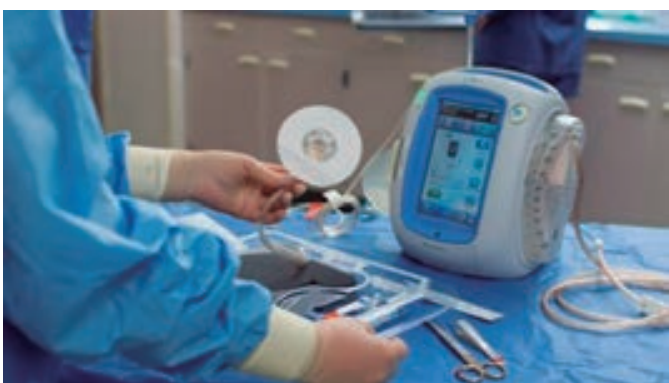

Figura 2: Terapia de presión negativa con sistema Vacuum Assisted Closure (KCI Co. USA).

vía respiratoria, no por vía tópica. La terapia de oxígeno hiperbárico estimula la cicatrización a través de vías fisiológicas y farmacológicas, que incluyen la completa saturación de la hemoglobina, el aumento de la difusión de oxígeno de los glóbulos rojos a los tejidos, la estimulación de la angiogénesis, el efecto bacteriostático y bactericida al estimularse los procesos oxidativos de destrucción bacteriana, la disminución del edema, la estimulación de la síntesis de óxido nítrico y la reducción en la producción de radicales libres, por lo que es útil en síndromes de reperfusión ${ }^{22}$ (Figura 3). Se indica en pie diabético infectado, osteomielitis crónica refractaria, infecciones necrosantes de tejidos blandos, síndromes de reperfusión, heridas secundarias a radioterapia y osteonecrosis por radioterapia.
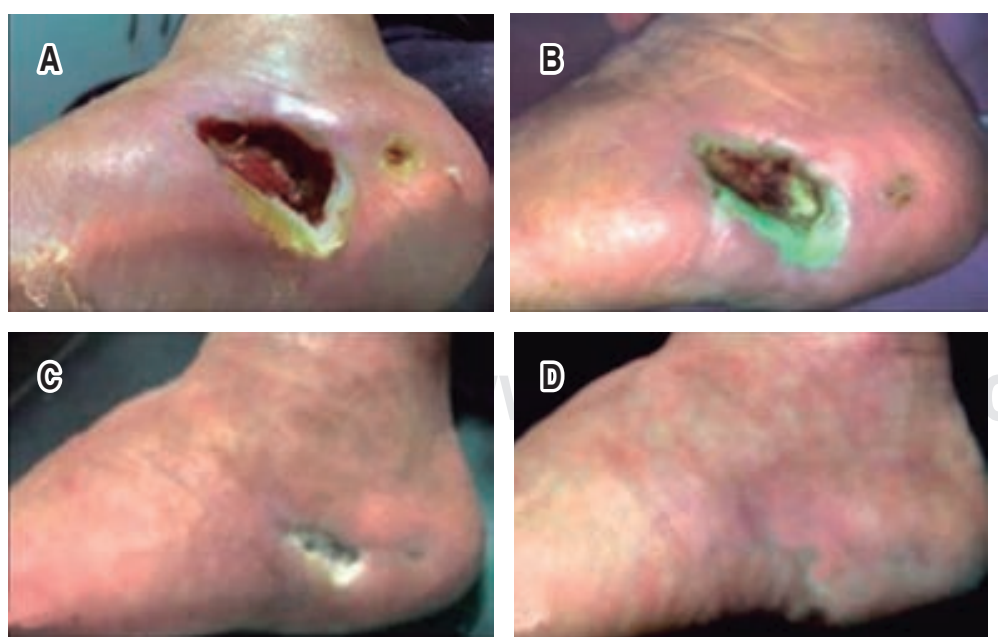

Figura 3: Evolución de lesión por pie diabético manejado con cámara hiperbárica.

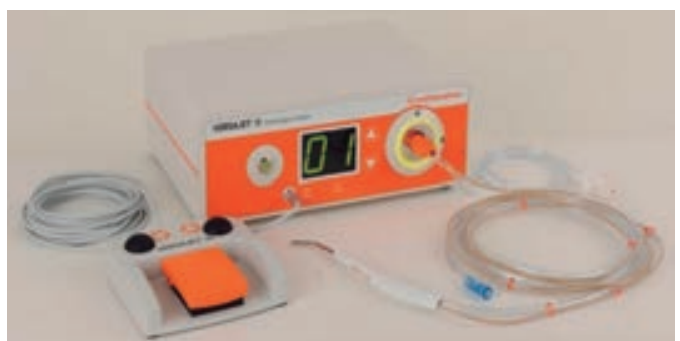

Figura 4: Versajet ${ }^{\circledR}$.

Es muy importante recalcar que el uso de esta terapia se basa en un adecuado aporte de oxígeno a los tejidos, garantizado por buena perfusión distal, proporcionada por conductos arteriales abiertos, por lo que los pacientes deben tener un examen vascular normal para someterse a la terapia de oxígeno hiperbárico. ${ }^{23}$

\section{Sistema de hidrobisturí/ hidrocirugía (Versajet ${ }^{\circledR}$ )}

Es un sistema de limpieza y desbridamiento quirúrgico que se enmarca en la «hidrocirugía». La hidrocirugía consiste en la utilización de chorros de agua a alta velocidad en herramientas quirúrgicas eléctricas. Este sistema produce un chorro de fluido a alta velocidad que crea una corriente de vacío en el extremo de la pieza de mano que aspira los tejidos blandos y que se adapta a todo tipo de heridas.

El sistema Versajet ${ }^{\circledR}$ consta de una consola de energía reutilizable, con pedal de activación, una pieza de mano desechable $\left(15^{\circ} / 14 \mathrm{~mm}\right.$, $45 \% / 14 \mathrm{~mm}, 45 \%$ mm), un tubo de montaje en conjunto con solución salina estéril y un recipiente con nivel de residuos para aprovechar al máximo su eficacia.

El sistema de hidrocirugía de Versajet $^{\circledR}$ permite a los cirujanos sujetar, cortar y extirpar el tejido dañado y cualquier partícula extraña de forma muy precisa, evitando los traumas asociados y pérdida de tejido viable necesario para la regeneración a las otras modalidades quirúrgicas. Se puede desbridar en un solo paso y con un solo instrumento (Figura 4). ${ }^{24}$

\section{Biodesbridamiento}

Entre los diferentes tipos de técnicas para el retiro de material necrótico de las heridas, el 
quirúrgico es el más importante. No obstante, algunas veces no se puede realizar, por lo que se deben usar otras técnicas. Una de las más antiguas, pero poco usadas, es el llamado biodesbridamiento, que utiliza larvas cultivadas estériles de la especie Lucilia sericata. En su proceso de crecimiento antes de convertirse en moscas, las larvas están ávidas de nutrientes y curiosamente consumen grandes cantidades de tejido necrótico, respetando el tejido sano y estimulan la aparición de tejido de granulación. Inclusive, tienen capacidad bactericida y bacteriostática por las secreciones propias de la larva o consumo de bacterias de la herida. Esta técnica de desbridamiento está plenamente avalada por la literatura y tiene sus indicaciones muy precisas. Debe ser utilizada por personal entrenado y con conocimiento del ciclo de vida de las larvas. ${ }^{25,26}$

\section{Sustitutos dérmicos}

Los sustitutos de piel son un grupo de materiales con los cuales se cubren heridas dérmicas para suplir las funciones de la piel. Pueden adquirirse de otros humanos, animales o producirse en el laboratorio. Han alcanzado un gran desarrollo y en la actualidad se cuenta con más de ocho de estos prototipos disponibles en el mercado. ${ }^{27}$ Se clasifican en dos tipos: biológicos o sintéticos, con dos subdivisiones: temporales o permanentes. ${ }^{28}$

\section{Biológicos temporales}

Membrana amniótica: se utiliza en quemaduras de espesor parcial. Por su bajo costo se utiliza en países donde el acceso a otros sustitutos es limitado. Tiene como desventaja el riesgo de transmisión de enfermedades.

Oasis ${ }^{\circledR}$ (Smith \& Nephew, Inc. Smith \& Nephew Wound Management. U.K.): la producción de este xenoinjerto es a base de submucosa de intestino delgado porcino. Su desventaja es que puede provocar incompatibilidad genética e inmunológica. No debe ser aplicado cuando hay exudado excesivo, sangrado o si hay infección.

Aloinjertos cadavéricos: se utilizan como injertos de espesor grueso y es un método temporal para el cierre de heridas que optimiza el sistema inmunológico del paciente proporcionando factores de crecimiento y citocinas para provocar quimiotaxis y proliferación celular; sin embargo, las células de Langerhans siguen activas, lo que puede provocar el rechazo de este aloinjerto. ${ }^{29}$

\section{Biológicos permanentes}

Apligraf $^{\circledR}$ (Organogenesis Inc. Living Technology. New Jersey, USA): compuesto de fibroblastos neonatales y queratinocitos que son colocados en una matriz de colágena bovina tipo I. Con el tiempo, el componente dérmico se cubre de queratinocitos neonatales que crecen en una capa y posteriormente se estratifican. ${ }^{30}$ Se recomienda su uso en úlceras venosas crónicas. Se contraindica en alergias al componente bovino y en heridas infectadas. ${ }^{31}$

Matriderm ${ }^{\circledR}$ (MedSkin Solutions Dr. Suwelack AG. Billerbeck, Germany): matriz extracelular de colágena bovina con elastina. Se utiliza para el tratamiento de heridas profundas de la dermis; mientras el tejido va creciendo, esta matriz se reabsorbe $y$ desaparece. $^{32}$

Alloderm ${ }^{\circledR}$ (LifeCell Corporation. Bridgewater, NJ, USA). Se fabrica mediante el procesamiento de piel cadavérica, esto da lugar a una dermis libre de células responsables de la respuesta antigénica en los aloinjertos, reduciéndola a una membrana basal y a una matriz dérmica de colágena, donde la nueva piel humana se puede regenerar. ${ }^{29}$ Es inmunológicamente inerte, pero tiene como desventaja bajo riesgo de transmitir enfermedades y está contraindicado en heridas infectadas o no vascularizadas. ${ }^{31}$

Epifast $^{\circledR}{ }^{\circledR}$ (Bioskinco S.A. de C.V. Estado de México, México): es el primer equivalente de piel viva, desarrollado a partir del cultivo de células epidérmicas humanas que se colocan sobre una capa de gasa vaselinada. Reduce el tiempo de epitelización hasta en $50 \%$ de las lesiones causadas por quemaduras, úlceras, dermoabrasiones, áreas donadoras y otras afecciones cutáneas. Disminuye el tiempo de recuperación del paciente, reduce la fibrosis y el dolor $y$ protege contra infecciones. 


\section{Sintéticos temporales}

Se forman de moléculas no biológicas o polímeros no presentes en la piel normal, con la finalidad de permitir el cubrimiento por células epiteliales así como el crecimiento de fibroblastos y vasos sanguíneos. Su ventaja es que evitan que se active la respuesta inmunológica.

TransCyte ${ }^{\circledR}$ (Smith \& Nephew, Inc. Smith \& Nephew Wound Management. U.K): consiste en una membrana polimérica y células neonatales de fibroblastos cultivadas bajo condiciones asépticas in vitro en una malla de nylon cubierta con colágena dérmica de porcino unida a una membrana de silicón, así esta membrana brinda una epidermis sintética al momento de aplicarse. Tiene la ventaja de ser transparente permitiendo un monitoreo directo del lecho de la herida. ${ }^{29}$

Biobrane $^{\circledR}$ (Smith \& Nephew, Inc. Smith \& Nephew Wound Management. U.K): está compuesto de un tejido de nylon resistente unido mecánicamente a una capa ultradelgada de goma de silicón; ambas capas poseen péptidos de colágena derivados de piel de cerdo. Permite su aplicación a heridas irregulares y es transparente. No debe permanecer más de dos semanas porque existe la posibilidad de que los fibroblastos se entrelacen con la malla. ${ }^{32}$

\section{Sintéticos permanentes}

Integra ${ }^{\circledR}$ (Integra LifeSciences Holdings Co. Plainsboro, NJ. USA): consiste en colágena bovina, condroitin-6-fosfato y una membrana de silicón. Se utiliza en heridas o defectos parcialmente profundos. La dermis del paciente se integra con la colágena bovina y se va formando nueva piel y cuando es satisfactoria la regeneración se retira la capa de silicón. ${ }^{33}$

Dermagraft ${ }^{\circledR}$ (Organogenesis Inc. Living Technology. La Jolla, CA, USA): es un derivado del cultivo de fibroblastos humanos neonatales; es una matriz sintética que permanece sobre una malla bioabsorbible. Después de que la malla se reabsorbe (un mes), se coloca un autoinjerto para la recuperación completa. ${ }^{30}$ Está indicado en úlceras diabéticas, quemaduras, reconstrucción mamaria, reconstrucciones de membrana timpánica y de septum nasal. ${ }^{31}$ No se debe usar en heridas infectadas, con trayectos fistulosos o con hipersensibilidad al producto. ${ }^{31}$

\section{TERAPIAS MÁS ACTUALES}

\section{Factores de crecimiento}

Las heridas crónicas se caracterizan por una disminución en la concentración y producción de factores de crecimiento, que es debida a la inhibición inflamatoria de las células que se encuentran en el lecho de las heridas.

En 1962, Cohen publicó que la purificación de extractos de la glándula submaxilar daba lugar a la separación temprana de los párpados y a la erupción de los incisivos en ratones, lo que finalmente condujo al aislamiento del primer factor de crecimiento: el factor de crecimiento epidérmico. ${ }^{34}$

Estudios han demostrado que uno de los factores de crecimiento más importantes es el factor de crecimiento derivado de las plaquetas (platelet derived growt factor, PDGF). Esta sustancia se ha podido producir por técnica de recombinación genética y se utiliza como estimulante de la cicatrización. Está especialmente indicada en pacientes con úlceras de origen neuropático diabético y es el único factor de crecimiento aprobado por la Food and Drug Administration (FDA), cuya efectividad se ha comprobado con estudios aleatorios. Se conoce como Regranex ${ }^{\circledR}$ (becaplermin $0.01 \%$ gel-Ortho McNeil diagnóstico y tratamiento Pharmaceutical, Johnson \& Johnson). ${ }^{35}$

\section{Terapia con células madre}

Las células madre son células que pueden diferenciarse en muchos tipos celulares y pueden ser útiles para la curación de heridas. Las células madre derivadas de adipocitos son cultivadas a partir de tejido extraído por liposucción y se ha estudiado su uso en heridas crónicas, demostrando que pueden acelerar su cierre. ${ }^{36}$ Estas células se diferencian en células epiteliales y endoteliales y secretan citoquinas angiogénicas, ayudando a la neovascularización; también se ha demostrado que promueven la proliferación de fibroblastos por contacto y por activación paracrina. ${ }^{37,38}$

Las células madre derivadas de la médula ósea promueven la cicatrización aumentando la población de fibroblastos y la producción 
de colágena en heridas crónicas que no han mejorado con las terapias convencionales. ${ }^{39,40}$

Se ha demostrado por inmuhistoquímica que las células madre derivadas del cordón umbilical se diferencian en queratinocitos en el tejido con heridas. ${ }^{40,41}$ Se han hecho estudios donde se demuestra que el uso de fibroblastos derivados de estas células en heridas experimentan una epitelización más rápida, organizada y más delgada. ${ }^{41}$

\section{Terapia génica}

Se ha estado estudiando la inserción de genes en la piel, ya sea de forma tópica o inyectada en la forma de vectores (éstos se encargan de insertar ADN en los genes humanos) virales y no virales. La forma no viral tiende a ser menos costosa y con menor riesgo de infección. En diversos estudios se ha comprobado que esta terapia promueve la granulación, vascularización y epitelización y mejora la calidad de la cicatriz. Por esto, Margolis y colaboradores realizaron en 2009 un experimento donde se inyectó un gen de adenovirus en úlceras crónicas, demostrando que su aplicación era segura y factible, teniendo como resultado tejido de granulación y la curación de la herida de difícil manejo. Sin embargo, se deben continuar estos experimentos para asegurar que esta terapia es segura y factible para la curación de heridas, tanto agudas como crónicas de difícil manejo. ${ }^{41}$

\section{DISCUSIÓN}

Desde tiempos remotos el hombre ha buscado la mejor manera de manejar las heridas con el único objetivo de formar tejido viable para su cierre adecuado. Con la complejidad que caracteriza el proceso de curación de heridas es claro que un solo agente o modalidad de tratamiento no puede servir para todas las heridas, por lo que cada una debe ser evaluada para optimizar su curación.

En la actualidad, la manera indicada de manejar las heridas crónicas es por medio de la curación avanzada y se considera una mala práctica la utilización de productos pasivos para el manejo de heridas crónicas, más aún sin la implementación de protocolos serios de diagnóstico y tratamiento.
La curación avanzada no es una moda en el actuar de los cirujanos, sino una forma de tratamiento avalada por evidencia seria. La curación avanzada, al ser más espaciada y con apósitos de alta tecnología y más fáciles de aplicar, ha demostrado ser más cómoda tanto para el paciente como para el prestador de salud. Además, múltiples estudios han hecho evidente la mayor costo-efectividad que tiene la curación avanzada sobre la curación tradicional y su capacidad notable de ahorro.

Se han estado investigando otras modalidades que estimulen la creación de tejido de granulación, que incluyen la utilización de factores de crecimiento, células madre y más recientemente la terapia génica, que parece prometedora; sin embargo, se necesitan más estudios para confirmar su efectividad.

\section{REFERENCIAS}

1. Lyons AS, Petrucelli RJ. Historia de la medicina. Primera edición. España. Ed. 1981 (Doyma).

2. Barquin M. Historia de la medicina. 8a edición. México: Ed. 2001 (Méndez Editores).

3. Ramírez AR, Dagnino UB. Curación de heridas. Antiguos conceptos para aplicar y entender su manejo avanzado. Cuad Cir 2006; 20: 92-99.

4. Brunicardi FC, Andersen DK, Billiar TR, Dunn DL, Hunter JG, Pollock RE. Schwartz. Principios de cirugía. Tomo I. 10å edición. México: Ed. 2015. (McGraw-Hill Interamericana).

5. Winter G, Scales J. Effect of air drying and dressings on the surface of a wound. Nature 1963; 197: 3648.

6. Furie B, Furie BC. Mechanisms of thrombus formation. N Engl J Med 2008; 359: 938-949. Available in: http:// dx.doi.org/10.1056/NEJMra0801082

7. Broughton G, Janis JE, Attinger CE. Wound healing: an overview. Plast Reconstr Surg 2006; 117: 1e-S32e-S supplement). Available in: http://dx.doi. org/10.1097/01.prs.0000222562.60260.f9

8. Janis JE, Kwon RK, Lalonde DH. A practical guide to wound healing. Plast Reconstr Surg 2010; 125 : 230e-244e.

9. Diegelmann RF. Analysis of collagen synthesis. Methods Mol Med 2003; 78: 349-358. Available in: http:// dx.doi.org/10.1385/1-59259-332-1:349

10. World Union of Wound Healing Societies (WUWHS). Diagnóstico y heridas. Documento de consenso [online]. Londres: MEP Ltd; 2008.

11. Mosquera-Fernández A, Giralt de Veciana E, González de la Torree H, Lluch Fruns J, Perdomo Pérez E et al. Aplicación del concepto "preparación del lecho de la herida" en el abordaje local de las lesiones crónicas. El Peu [Online]. 2010; 30 (3): 120-128.

12. European Wound Management Association (EWMA). Position Document: Wound Bed Preparation in Practice. London: MEP Ltd., 2004. 
13. Tizón-Bouza E, Pazos-Platas S, Álvarez-Díaz M, Marcos Espino MP, Quintela-Varela ME. Cura en ambiente húmedo en úlceras crónicas a través del concepto TIME. Recomendaciones basadas en la evidencia. Enferm Dermatol [online]. 2013; 7 (20): 31-42.

14. Palomar Llatas F, Fornes Pujalte B, Tornero Pla A, Muñoz. Escala A. Valoración Fedpalla de la piel perilesional. Enferm Dermatol 2007; 1 (0): 36-38.

15. Rivington LG. Hanging wet-to-dry dressings out to dry, advanced in skin and wound care. Adv Wound Care 2002; 15: 279-284.

16. Krasner D, Sibbald G. Chronic wound care. 3rd ed. San Diego: Appleton and Lange; 2002; 12: 120-140.

17. Andrade P, Sepúlveda S, González J. Curación avanzada de heridas. Revista Chilena de Cirugía 2004; 56: 396-403.

18. Trent J, Falabella A, Eaglestein W, Kirsner R. Venous ulcers: pathophysiology and treatment options. Ostomy Wound Manage 2005; 51 (Suppl. 2a): 45-50.

19. Lazaurus GS. Definitions and guidelines for assessment of wounds and evaluation of healing. Wounds 1994; 130: 489.

20. Vranck M, Slama N, Preuss S. Wet wound healing. Plast Reconstr Surg 2002; 110: 1680.

21. Jiménez CE. Terapia de presión negativa, experiencia clínica con 87 casos y revisión de la literatura. Rev Colomb Cir 2007; 43: 23-27.

22. La Van FB, Hunt Tk. Oxygen and wound healing. Clin Plast Surg 1990; 17: 463-472.

23. Feldemeier JJ. Hyperbaric oxygen 2003: indications and results. Hyperbaric Oxygen Therapy Committee report. Kensington, MD; Undersea and Hyperbaric Medical Society, 2003.

24. Gs19p Versajet: a novel approach to debridement. ANZ J Surg 2007; 77 (Suppl 1): A30. Available in: http:/wound.smith-nephew.com/au/node. asp? nodeld $=3993$.

25. Sherman RA, WYLE F, VULPE M. Maggot therapy for treating pressure ulcers in spinal cord injury patients. J Spinal Cord Med 1995; 18: 71-74.

26. Sherman RA. A new dressing design for use with maggot therapy. Plast Reconstr Surg 1997; 100: 451 456.

27. Mirastschijsk U, Bugdahl R, Rollman O, Johansson BR, Ágran MS. Epithelial regeneration from bioengineered skin explants in culture. $\mathrm{Br} /$ Dermatol 2006; 154 42-49. Available in: http://dx.doi.org/10.1111/j.13652133.2005.06997.x

28. Alvarez LJA, Flores OM, Hernandez GR, Martinez $\mathrm{MH}$, Escamilla OC, Rivera SG. Una segunda piel: tratamiento con sustitutos dérmicos. Rev Med 2012; 4: $37-41$

29. Zaulyanov L, Kirsner RS. A review of a bi-layered living cell treatment (Apligraf ${ }^{\circledR}$ ) in the treatment of venous leg ulcers and diabetic foot ulcers. Clin Interv Aging 2007; 2: 93-98.
30. Fan, K, Tang J, Escandon J, Kirsner RS. State of art in topical wound-healing products. Plast Reconstr Surg 2011; 127: 44S-59S

31. Atherton DD, Tang R, Jones I, Jawad M. Early excision and application of matriderm with simultaneous autologous skin grafting in facial burns. Plast Reconstr Surg 2010; 125 (2): 60e-61e. Available in: http:// dx.doi.org/10.1097/PRS.0b013e3181c725e5

32. Robson, MC, Phillips TJ, Falanga V, Odenheimer DJ, Parish LC, Jensen JL et al. Randomized trial of topically applied repifermin (recombinant human keratinocyte growth factor-2) to accelerate wound healing in venous ulcers. Wound Repair Regen 2001; 9: 347-352.

33. Fette A. Integra artificial skin in use for full thickness burn surgery: benefits or harms on patient outcome. Technol Health Care 2005; 13: 463-468.

34. Nie C, Yang D, Xu J, Si Z, Jin X, Zhang J. Locally administered adipose-derived stem cells accelerate wound healing through differentiation and vasculogenesis. Cell Transplant 2011; 20: 205-216.

35. Steed Dl. Clinical evaluation of recombinant human platelet derived growth factor for the treatment of lower extremity diabetic ulcers. J Vasc Surg 1995; 21: 71-81.

36. Kim WS, Park BS, Sung JH, Yang JM, Park SB, Kwak SJ et al. Wound healing effect of adipose-derived stem cells: A critical role of secretory factors on human dermal fibroblasts. J Dermatol Sci 2007; 48: 15-24.

37. Fathke C, Wilson L, Hutter J, Kapoor V, Smith A, Hocking A et al. Contribution of bone marrow-derived cells to skin: Collagen deposition and wound repair. Stem Cells 2004; 22: 812-822.

38. Badiavas EV, Falanga V. Treatment of chronic wounds with bone marrow-derived cells. Arch Dermatol 2003; 139: 510-516.

39. Morton LM, Phillips TJ. Wound healing update. Semin Cutan Med Surg 2012; 31: 33-37.

40. Luo G, Cheng W, He W, Wang X, Tan J, Fitzgerald M et al. Promotion of cutaneous wound healing by local application of mesenchymal stem cells derived from human umbilical cord blood. Wound Repair Regen 2010; 18: 506-513.

41. Zebardast N, Lickorish D, Davies JE. Human umbilical cord perivascular cells (HUCPVC): A mesenchymal cell source for dermal wound healing. Organogenesis 2010; 6: 197-203.

Conflicto de intereses: Los autores declaran no tener conflicto de intereses.

Financiamiento: Los autores no recibieron patrocinio para llevar a cabo este trabajo.

Correspondencia:

Dr. Gastón Domínguez-Saavedra

Calzada Francisco I Madero Núm. 1291

25000, Saltillo, Coahuila de Zaragoza, México

E-mail: gaston_dot@hotmail.com 